\title{
Selective oxidation of 4-tert-butylphenol by hydrogen peroxide in the presence of titanosilicates
}

\author{
R. R. Talipova ${ }^{1}$ R. U. Kharrasov ${ }^{1}$ M. R. Agliullin ${ }^{1,2}$ - A. D. Badikova ${ }^{3}$. \\ B. I. Kutepov ${ }^{1,2}$
}

Received: 26 February 2016/ Accepted: 3 October 2016/Published online: 25 October 2016

(C) The Author(s) 2016. This article is published with open access at Springerlink.com

\begin{abstract}
The catalytic transformations of 4-tertbutylphenol in hydrogen peroxide solutions were investigated in the presence of crystalline and amorphous titanosilicates and titanium oxide. The TS-1 microporous crystalline titanosilicate was shown to exhibit low activity in the 4-tert-butylphenol transformation due to the steric limitations on the diffusion of the substrate molecules towards catalytic active centers. Mesoporous amorphous titanosilicates were more selective in the 4-tert-butylcatechol formation than the titanium oxide. The selectivity to 4-tert-butylcatechol in the presence of the $\mathrm{TiO}_{2}$ did not exceed $20 \mathrm{~mol} \%$. The maximum $53 \mathrm{~mol} \%$ selectivity value to 4-tert-butylcatechol was shown to occur over the amorphous mesoporous titanosilicate containing $1.9 \mathrm{wt} \%$ of $\mathrm{Ti}$, the 4-tert-butylphenol conversion value being equal to $42 \mathrm{~mol} \%$.
\end{abstract}

Keywords 4-tert-butylphenol · 4-tert-butylcatechol . Hydrogen peroxide Titanium oxide Titanosilicate

\section{B. I. Kutepov}

kutepov_bi@mail.ru; ink@anrb.ru

1 Institute of Petrochemistry and Catalysis of Russian Academy of Sciences, 141 Pr. Oktyabrya, Ufa 450075, Russian Federation

2 Ufa State Petroleum Technological University, 1 Kosmonavtov St., Ufa 450062, Russian Federation

3 Bashkir State University, 32 Frunze St., Ufa 450074, Russian Federation

\section{Introduction}

4-tert-butylcatechol (4-TBC) was widely used as a restraining agent in the diene hydrocarbons polymerization; as a stabilizing additive for polymer materials, unsaturated aldehydes, and synthetic ethylcellulose-based resins; as an oxidation preventer for animal fat, oil, and wax [1-4].

Well-known techniques for 4-TBC synthesis were based on the alkylation of catechol by isobutylene or iso-butanol in the presence of inorganic acids, mainly sulphuric acid $[3,4]$. The industrial production process was conducted in two stages: first, by the alkaline melting of o-chlorophenol or o-phenylsulphonic acid, they obtain the starting catechol, which, in its turn, was alkylated over KU-2 cationite with iso-butyl alcohol. The drawbacks of the process were the following: the formation of di- and tri- alkyl catechol derivatives, the undesired waste effluent formation, and the complex production technology.

The selective oxidation of 4-tert-butylphenol (4-TBP) by $\mathrm{H}_{2} \mathrm{O}_{2}$ solutions in the presence of titanosilicate catalysts could become a promising alternative for the 4-TBC production. However, there was no information in the literature regarding this matter.

Titanosilicates were widely known as an important catalysts with high activities and selectivities coupled with environmentally benign catalytic performance and play a vital role in catalytic oxidation with $\mathrm{H}_{2} \mathrm{O}_{2}$ [5]. Despite the fact that to date, two types of titanosilicate (Ti-MFI and TiMWW) were used in the industry, the TS- 1 remained the industrial standard catalyst for oxidation reactions [5-7]. TS-1 was a crystalline microporous material of the ZSM-5 zeolite structure, where a number of silicon atoms in the lattice were substituted by the isomorphous titanium atoms. It was possible to expect that this catalyst would be low 
effective for the bulky 4-TBP molecules on account of the steric restrictions. Therefore, the aim of this study was to investigate the reaction of 4-TBP oxidation by hydrogen peroxide solutions in the presence of crystalline and amorphous titanosilicates of different porous structures.

\section{Experimental}

\section{Catalyst preparation}

The $\mathrm{TiO}_{2}$ was obtained by the hydrolysis of $\mathrm{TiCl}_{4}$ in an ammonia-alcohol solution $\left(60 \mathrm{mmol} \mathrm{TiCl}_{4}\right.$ and $360 \mathrm{mmol}$ $\mathrm{NH}_{4} \mathrm{OH}$ in $50 \mathrm{ml}$ ethanol and $50 \mathrm{ml}$ water). $\mathrm{NH}_{4} \mathrm{Cl}$ was further removed by the stages of rinsing and thermal treatment at $550{ }^{\circ} \mathrm{C}$ for $6 \mathrm{~h}$.

A sample of TS-1 crystalline titanosilicate containing $1.9 \mathrm{wt} \%$ of $\mathrm{Ti}$ was synthesized according to the technique described in [6].

The mesoporous amorphous titanosilicate catalyst samples were prepared by the sol-gel technique using the commercially available ethylsilicate-40 (ES-40) and titanium chloride alcohol solutions [8, 9]. Typically, $70 \mathrm{mmol}$ of ES-40 was dissolved in $20 \mathrm{ml}$ ethanol and $12 \mathrm{ml}$ water. Then, the solution of $\mathrm{TiCl}_{4}(0.87 \mathrm{mmol}$-for sample TSm1; $1.75 \mathrm{mmol}$-for sample TSm-2; $3.50 \mathrm{mmol}$-for sample TSm-3) in $15 \mathrm{ml}$ ethanol was added under stirring to produce a clear transparent gel. After gelation at $60{ }^{\circ} \mathrm{C}$ for 24-48 h, the solution of $10 \mathrm{mmol}$ of ammonia in $20 \mathrm{ml}$ ethanol was added. Alcogel was aged for 2 days at room temperature. The conventional drying of alcogel $(12 \mathrm{~h}$ at $60{ }^{\circ} \mathrm{C}$ and $8 \mathrm{~h}$ at $120^{\circ} \mathrm{C}$ ) and calcination at $550{ }^{\circ} \mathrm{C}$ in air for $6 \mathrm{~h}$ yielded xerogel (sample TSm-1, containing $1.0 \mathrm{wt} \% \mathrm{Ti}$; sample TSm-2, containing $1.9 \mathrm{wt} \% \mathrm{Ti}$; sample TSm-3, containing $3.7 \mathrm{wt} \% \mathrm{Ti}$ ).

\section{Catalyst analysis}

Compositions of the synthesized titanosilicates were analyzed with the energy-dispersive X-ray fluorescent Shimadzu EDX-800HS spectrometer equipped with the rhodium anode $\mathrm{X}$-ray tube operating at the voltage of $15-50 \mathrm{kV}$ and the current of $20-1000 \mu \mathrm{A}$, the pinhole of 3-5 mm, under vacuum.

The phase composition of samples was determined with the D8 Advance Bruker X-ray diffractometer using Cuк $\alpha$ emission $(\lambda=1,5418 \AA$ Ni-filter, $25 \mathrm{kV}, 20 \mathrm{~mA}$, $2 \Theta=10-75,2 \mathrm{~min}^{-1}$ ). The qualitative and quantitative phase analysis was performed using the POWDER CELL 2.4 application program with the PCPDFWIN powder database.

The framework IR spectra of the titanosilicates were recorded in an Advance BRUKER Vertex $70 \mathrm{~V}$ Fourier IR spectrometer. The sample pellets were press-molded with $\mathrm{KBr}$, placed into the working cell, and calcined at $350{ }^{\circ} \mathrm{C}$ followed by recording the IR absorption spectra within the range of $4000-400 \mathrm{~cm}^{-1}$.

The textural characteristics were determined by the lowtemperature nitrogen adsorption-desorption technique at $77 \mathrm{~K}$ using the Micromeritics ASAP-2020 sorption meter. Prior to the analysis, the samples were evacuated at $100-350{ }^{\circ} \mathrm{C}$ for $6 \mathrm{~h}$. The specific surface square area was calculated by the BET method at the relative partial pressure of $p / p_{0}=0.2$. The pore size distribution was calculated using the desorption curve and the BJH method, and the total pore volume being determined by $\mathrm{BJH}$ at the relative partial pressure of $p / p_{0}=0.95$. The volume of micropores in the presence of mesopores was determined using the t-method by Halsey [10].

The distribution of the $\mathrm{Ti}$ atoms in the silica framework was investigated using diffuse reflectance UV-Vis spectroscopy. DR UV-Vis spectra were recorded under ambient conditions on a Shimadsu UV-VIS 2501PC spectrometer.

\section{Oxidation procedure}

The 4-TBP conversion runs were performed using the bench-scale setup with the batch isothermal reactor equipped with the stirrer (200 rpm), backflow condenser, and thermometer. A $5 \mathrm{ml}$ aliquot of solvent (acetonitrile, acetone, ethanol), $0.09 \mathrm{~g}$ 4-TBP, and the calculated amount of the catalyst $(0.1-0.6 \mathrm{~g})$ were loaded into the reactor and stirred until the temperature became constant. Then, a required aliquot of the aqueous $35 \% \mathrm{H}_{2} \mathrm{O}_{2}$ solution $(0.06$, 0.12 , and $0.24 \mathrm{ml}$ ) was added into the reactor and the reaction start time was recorded. The feed 4-TBP concentration was $0.12 \mathrm{~mol} / \mathrm{l}$; the $4-\mathrm{TBP} / \mathrm{H}_{2} \mathrm{O}_{2}$ molar ratio was $1 / 1,1 / 2,1 / 4$. The experiments were run at 35,50 , and $75^{\circ} \mathrm{C}$ in the presence of $2.5-15 \mathrm{wt} \%$ of the catalyst in the mass of the feed reaction mix during 10-60 min. The grain size of the catalyst fraction used was $80-100 \mu \mathrm{m}$. In the preliminary experiments, the reaction mass obtained as a result of the experiment was separated from the catalyst by filtering, and the residual $\mathrm{H}_{2} \mathrm{O}_{2}$ content was determined by the iodometric titration. The high molecular weight products of the oxidative condensation were removed by filtering the reaction mix through the column loaded by the silica gel bed (the fraction of 100-200 $\mu \mathrm{m}$ ).

To obtain information on the stability of active Ti species in the solid matrix, the catalyst was reused five times. The catalyst was separated by filtration after each reaction, washed with acetonitrile, and then placed into a fresh reagent mixture. On the other hand, to demonstrate that the activity of catalyst was not due to the leaching of $\mathrm{Ti}$ species, an additional catalytic test was performed with 
filtering the reaction mix: the catalyst was fast filtered off at the reaction temperature $\left(75^{\circ} \mathrm{C}\right)$ and then the solution was further reacted for $60 \mathrm{~min}$ at $75^{\circ} \mathrm{C}$.

The products analysis was carried out by HPLC (HP 1050 with UV-detector) equipped with a $\mathrm{C} 18$ reverse-phase column and operated at $275 \mathrm{~nm}$ using $70 \% \mathrm{CH}_{3} \mathrm{CN}$ in water as a mobile phase. An internal substance, biphenyl, was used to quantify the 4-TBP and 4-TBC content.

\section{Results and discussion}

\section{Catalyst characterization}

According to the X-ray diffraction analysis, the $\mathrm{TiO}_{2}$ was the anatase form (Fig. 1a).

The diffraction pattern of TS-1 powder was characteristic for the crystalline microporous titanosilicate TS-1 [6] (Fig. 1b).

All titanosilicate samples TSm were completely amorphous and no separate crystalline phase of $\mathrm{TiO}_{2}$ (like anatase) was detected (Fig. 1c-e).

The IR spectrum of TS-1 and TSm samples was presented in Fig. 2. A peak assignable to the symmetric vibrational Ti-O-Si stretching can be seen at $\sim 960 \mathrm{~cm}^{-1}$; while peaks at $\sim 800$ and $\sim 1100 \mathrm{~cm}^{-1}$ can be attributed to the symmetric and asymmetric vibrational stretching $\mathrm{Si}-$ O-Si, characteristic of $\mathrm{SiO}_{4}$ units with tetrahedral coordination, respectively. A typical band near $550 \mathrm{~cm}^{-1}$ observed for TS-1 is due to the stretching vibration $\mathrm{SiO}_{4}$ of structural double five-membered rings in MFI-type molecular sieves framework [11]. This vibration is obviously not present in the amorphous titanosilicates.

Structural properties of synthesized samples were listed in Table 1.

It was shown from Table 1 that with increasing the $\mathrm{Ti}$ content in TSm samples titanosilicates, the specific surface area and the total pore volume were slightly decreased. This variation in the porous structure characteristics was attributed in [12] to the fact that when the Ti content in the titanosilicate increases, a part of it could exist as a separate oxide phase, leading to the variations in the porous structure.

Figure 3 presented the adsorption-desorption isotherms of TS-1 and TSm samples. The TS- 1 sample exhibited the isotherm of type I without the hysteresis loop indicating the microporous materials. All TSm samples showed isotherm type IV with a type $\mathrm{H} 3$ hysteresis loop according to the IUPAC classification [10]. The formation of type IV isotherms indicated the presence of mesopores and type H3 hysteresis loop associated with the presence of aggregates of plate-like particles that advance to slitshaped pores.
The pore size distribution (Fig. 4) derived from a BJH analysis of the desorption isotherm for mesoporous TSm samples showed a monomodal distribution centered at about $5 \mathrm{~nm}$. t-Plot analysis showed that the volume of micropores was negligible $\left(<0.02 \mathrm{~cm}^{3} / \mathrm{g}\right)$. Thus, all synthesized titanosilicates of the TSm series had the mesoporous structure with a rather narrow pore distribution.

According to DRS-UV (Fig. 5), both TS-1 and TSm samples had high titanium dispersion. TS-1 showed only a well-defined band at $210 \mathrm{~nm}$ which is attributed to the isolated $\mathrm{Ti}$ atoms in a tetrahedral coordination environment. The predomination of site-isolated titanium species in the amorphous mesoporous TSm samples is indicated by absorption bands centered at 216-238 nm. The samples with high $\mathrm{Ti}$ content showed a slightly long-wave shift along with a band broadening, thus indicating the appearance of higher coordinated $\mathrm{Ti}$ atoms in oligomeric $\mathrm{Ti}$ species [13]. The absence of a band at $330 \mathrm{~nm}$ showed that anatase was not present.

\section{Catalytic studies}

The preliminary runs were conducted to demonstrate that there were no transformations of 4-TBP and $\mathrm{H}_{2} \mathrm{O}_{2}$ in the absence of a catalyst. It should also be pointed out that none of the investigated catalysts caused any transformations of 4-TBP without hydrogen peroxide. The gaseous phase composition (either air or nitrogen gas) did not affect neither the 4-TBP conversion nor the reaction product composition. Thus, under the studied conditions, both the catalyst and $\mathrm{H}_{2} \mathrm{O}_{2}$ must simultaneously present in the reactor for any oxidative transformations of 4-TBP to occur.

Catalytic properties of the synthesized titanosilicate samples were investigated in the oxidative 4-TBP transformations in the $\mathrm{H}_{2} \mathrm{O}_{2}$ acetonitrile-aqueous solutions (Fig. 6). It can be seen that the 4-TBP conversion in the presence of the TS-1 sample did not exceed $3 \mathrm{~mol} \%$. The low activity of the crystalline microporous titanosilicate in the 4-TBP transformation was attributed to the steric restrictions on the diffusion of 4-TBP to the catalytic active centers. In the same time, the centers remained available for the much more less in size $\mathrm{H}_{2} \mathrm{O}_{2}$ molecules. It was proven by the rather high conversion factor of the oxidizing agent occurred due to the decomposition of the latter in the pores of the TS-1 sample.

Products of the 4-TBP conversion were 4-tert-butylcatechol (4-TBC) and high molecular weight products of the 4-TBP oxidative condensation (tars). Under the conditions indicated in Fig. 6, the 4-TBP conversion in the presence of TSm samples amounted $57 \mathrm{~mol} \%$; the maximum selectivity to 4 -TBC was $45 \mathrm{~mol} \%$. As the content of $\mathrm{Ti}$ increased from 1.0 to $3.7 \mathrm{wt} \%$ (the transition from TSm-1 
Fig. $1 \mathrm{X}$-ray diffraction pattern of $\mathrm{TiO}_{2}$ (a), TS-1 (b), TSm-1

(c), TSm-2 (d), and TSm-3 (e)
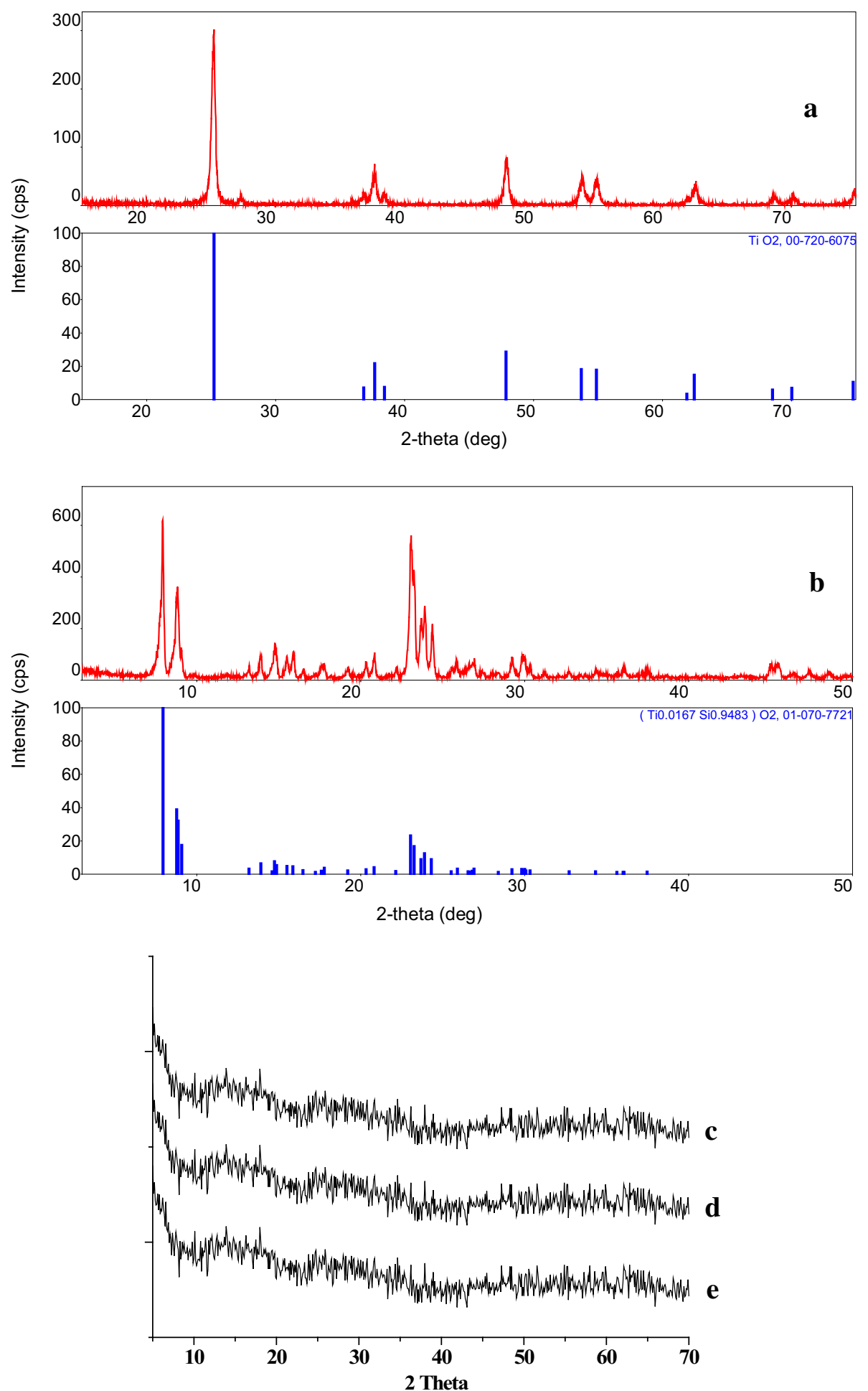

sample to the TSm-3 sample), the 4-TBP conversion values slightly increased from 51 to $57 \mathrm{~mol} \%$, whereas the selectivity to 4-TBC decreased from 45 to $38 \mathrm{~mol} \%$. This fact can be explained by the appearance of partially oligomerized titanium species as the content of $\mathrm{Ti}$ increased (according to DRS-UV, Fig. 5). In the presence of $\mathrm{TiO}_{2}$, the 4-TBP conversion was $30 \mathrm{~mol} \%$ and the 4-selectivity to 4-TBC did not exceed $20 \mathrm{~mol} \%$.

Thus, the mesoporous amorphous titanosilicates synthesized in this work were more selective in the 4-TBC formation than the titanium oxide and a contribution of the decomposition reaction of the oxidizing agent 

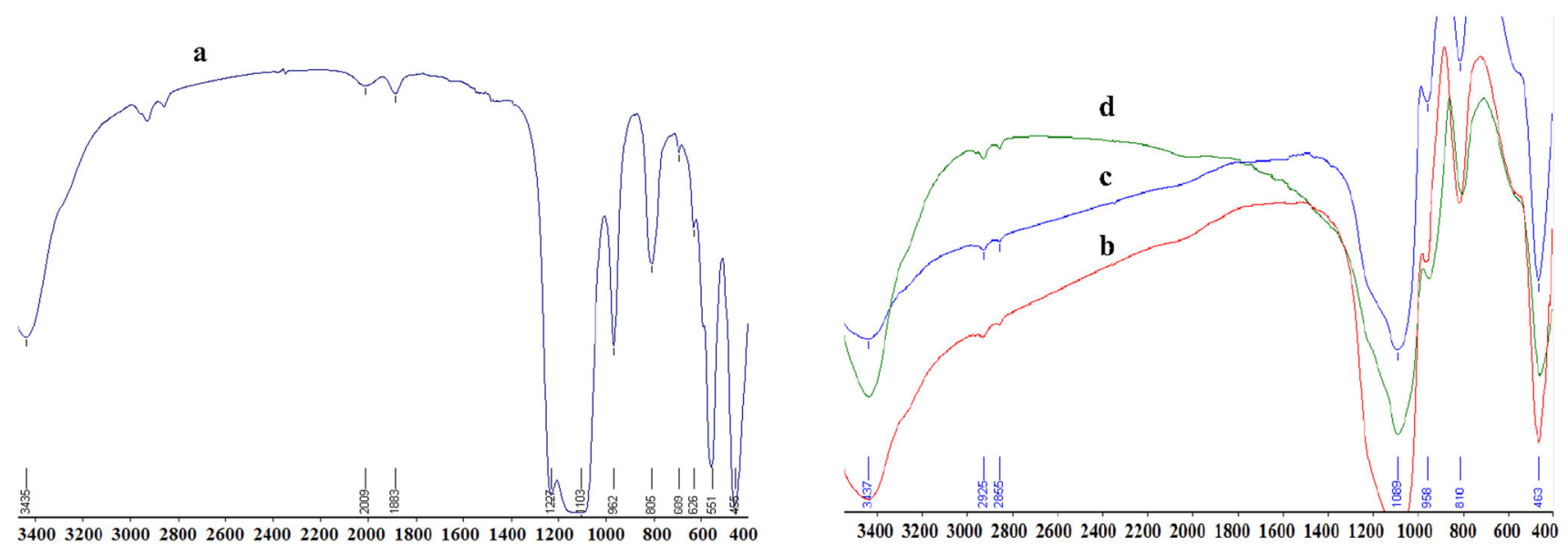

Fig. 2 IR spectra of TS-1 (a), TSm-1 (b), TSm-2 (c), and TSm-3 (d)

Table 1 Porous structure characteristics of the synthesized samples

\begin{tabular}{lccll}
\hline Sample & Ti content $(\mathrm{wt} \%)$ & Specific surface area $(\mathrm{BET})\left(\mathrm{m}^{2} / \mathrm{g}\right)$ & Mesopore volume $\left(\mathrm{cm}^{3} / \mathrm{g}\right)$ & Micropore volume $\left(\mathrm{cm}^{3} / \mathrm{g}\right)$ \\
\hline $\mathrm{TiO}_{2}$ & 59.9 & 50 & 0.26 & 0.02 \\
$\mathrm{TS}-1$ & 1.9 & 360 & - & 0.21 \\
$\mathrm{TSm}-1$ & 1.0 & 560 & 0.99 & 0.04 \\
$\mathrm{TSm}-2$ & 1.9 & 505 & 0.92 & 0.05 \\
$\mathrm{TSm}-3$ & 3.7 & 495 & 0.89 & 0.05 \\
\hline
\end{tabular}

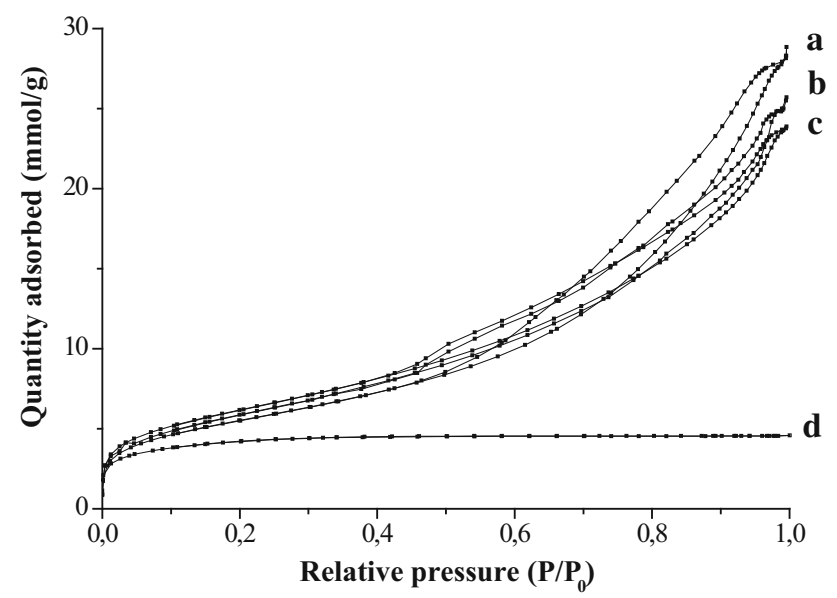

Fig. 3 Adsorption-desorption isotherms of TSm-1 (a), TSm-2 (b), TSm-3 (c), and TS-1 (d)

molecules into water and oxygen molecules was also less.

According to the data reported in [14], the Ti atoms of the crystalline titanosilicate TS-1 existed in the tetrahedral environment of SiO-groups. By reacting with $\mathrm{H}_{2} \mathrm{O}_{2}$ molecules, they formed hydroperoxo complexes [15] selective in phenol hydroxylation. Similarly, Ti atoms in the oxide were in the octahedral oxygen environment and exhibited

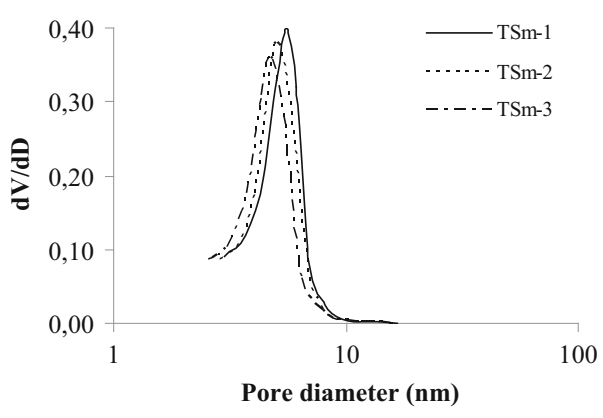

Fig. 4 Pore-size distribution for the TSm samples

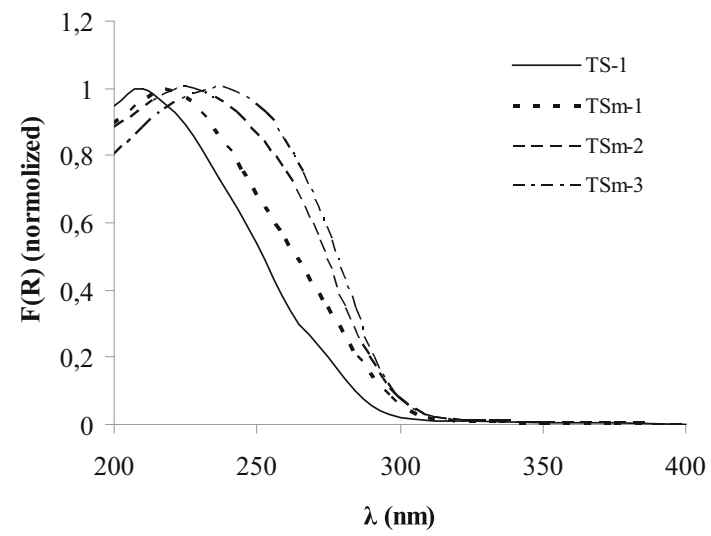

Fig. 5 DR UV-Vis spectra for TS-1 and TSm samples 

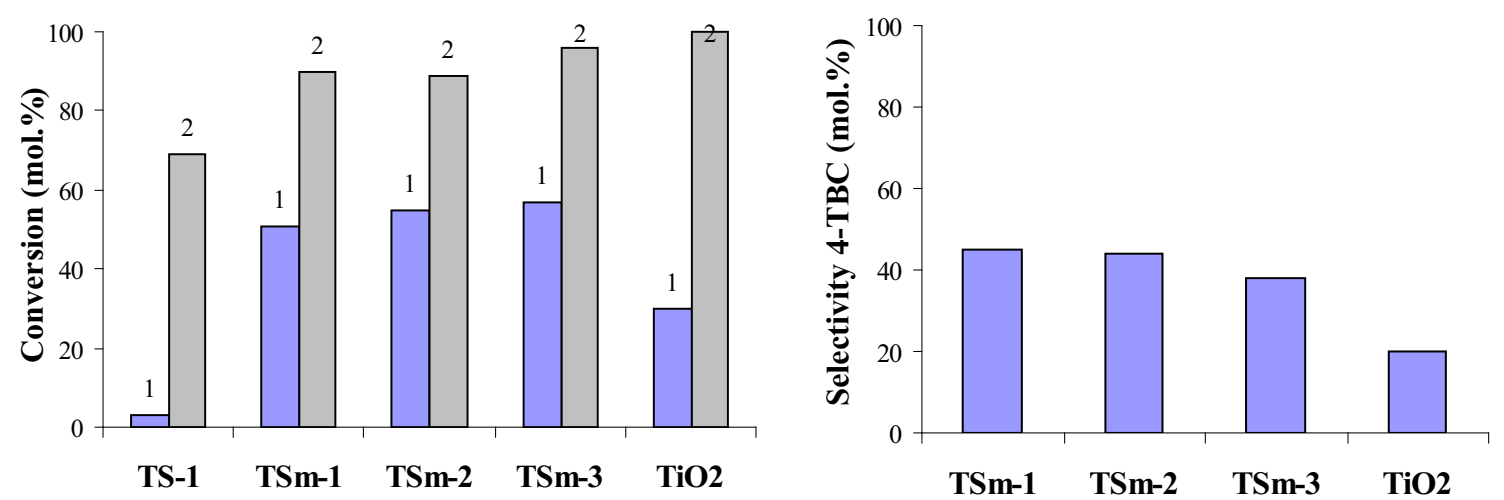

Fig. 6 Conversion of 4-TBP (1), $\mathrm{H}_{2} \mathrm{O}_{2}$ (2) and the selectivity to 4-TBC over Ti-containing catalyst (reaction conditions: 10 wt\% of the catalyst; $c^{0}(4-\mathrm{TBP})=0.12 \mathrm{~mol} / \mathrm{l} ; 4-\mathrm{TBP} / \mathrm{H}_{2} \mathrm{O}_{2}=1 / 2(\mathrm{~mol} / \mathrm{mol}) ; 5 \mathrm{ml}$ solvent; $\left.\left.75^{\circ} \mathrm{C} ; 60 \mathrm{~min}\right) 75^{\circ} \mathrm{C} ; 60 \mathrm{~min}\right)$

activity in the $\mathrm{H}_{2} \mathrm{O}_{2}$ decomposition. The presence of partially oligomerized titanium species catalyzed the reaction by radical chain mechanism to form products $\mathrm{C}-\mathrm{C}$ and $\mathrm{C}-$ O coupling [16]. Our results proved this conclusion.

During the condensation stage of synthesizing amorphous titanosilicates, the incorporation of $\mathrm{Ti}$ atoms into the silica matrix was possible through the partial substitution of silicon atoms in the silicon-oxygen tetrahedrons. The process was accompanied by the formation of the active centers similar to those in the TS- 1 . Therefore, the TSm samples were more selective in the 4-TBC formation than the titanium oxide ones. Meanwhile, the titanium complexes could precipitate as the highly dispersed crystalline hydroxide phase. After the thermal treatment, it became the dioxide phase and the active in $\mathrm{H}_{2} \mathrm{O}_{2}$ decomposition and not selective in the 4-TBC formation centers were formed on the surface of it.

\section{Effect of reaction parameters}

The application of a polar solvent is known [14] as the favorable factor to decrease the homolytic $\mathrm{H}_{2} \mathrm{O}_{2}$ decomposition that yields various radical oxo-intermediates and leads to the non-selective oxidation. Besides, similar to the phenol hydroxylation with $\mathrm{H}_{2} \mathrm{O}_{2}$ [17], we may assume that the reaction of the selective 4-TBP oxidation to 4-TBC with $\mathrm{H}_{2} \mathrm{O}_{2}$ over amorphous mesoporous titanosilicate also occurs via heterolytic oxygen atom transfer mechanism (electrophilic hydroxylation) [16]. And there is a number of recommended solvents for the latter, namely, water, methanol, ethanol, acetic acid, acetone, acetonitrile, DMSO, DMPA, nitromethane, and sulpholane [18]. In Fig. 7, the results of the 4-TBP oxidation by aqueous $\mathrm{H}_{2} \mathrm{O}_{2}$ solution in the presence of TSm-2 sample are given for different solvents, namely, acetonitrile, acetone, and ethanol. In acetone and ethanol solvents, the 4-TBP conversion values are close, the selectivity to $4-\mathrm{TBC}$ being higher in acetone than in ethanol. The highest 4-TBP conversion of

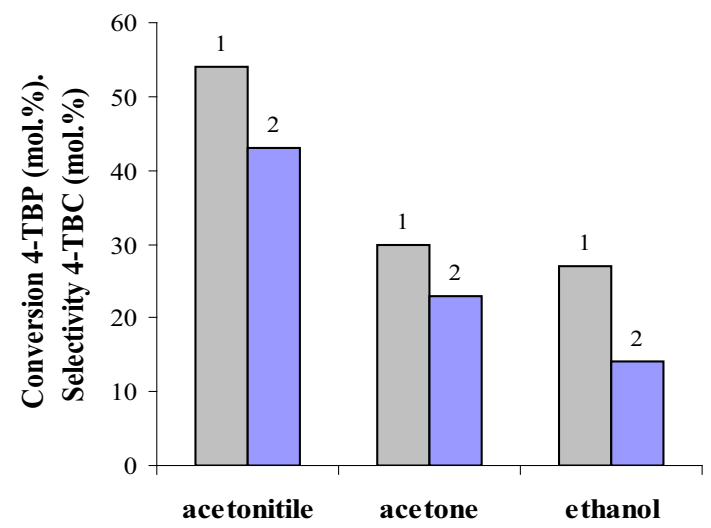

Fig. 7 Effect of solvent on the 4-TBP conversion (1) and on the selectivity to 4-TBC (2) (reaction conditions: $10 \mathrm{wt} \%$ of the TSm-2, $c^{0}(4-\mathrm{TBP})=0.12 \mathrm{~mol} / \mathrm{l}, 4-\mathrm{TBP} / \mathrm{H}_{2} \mathrm{O}_{2}=1 / 2(\mathrm{~mol} / \mathrm{mol}), 5 \mathrm{ml}$ solvent, $75{ }^{\circ} \mathrm{C}, 60 \mathrm{~min}$ )

$54 \mathrm{~mol} \%$ and the highest selectivity to $4-\mathrm{TBC}$ of $43 \mathrm{~mol} \%$ are observed in the acetonitrile medium.

Results of the studies presented in Table 2 illustrated the influence of the catalyst amount, temperature, and 4-TBP/ $\mathrm{H}_{2} \mathrm{O}_{2}$ molar ratio on the 4-TBP and $\mathrm{H}_{2} \mathrm{O}_{2}$ conversions and on the selectivity to 4-TBC in the presence of TSm-2 sample. It can be seen that the 4-TBP and $\mathrm{H}_{2} \mathrm{O}_{2}$ conversion values were minimum in the presence of $2.5 \mathrm{wt} \%$ of titanosilicate at $35^{\circ} \mathrm{C}$, being 11 and $23 \mathrm{~mol} \%$, respectively. The increase in temperature up to $75{ }^{\circ} \mathrm{C}$ caused more than 3-fold increase in the 4-TBP and $\mathrm{H}_{2} \mathrm{O}_{2}$ conversion up to 38 and $76 \mathrm{~mol} \%$, respectively. As well, the increase in temperature from $35^{\circ} \mathrm{C}$ up to $75{ }^{\circ} \mathrm{C}$ led to the increase in the selectivity to 4-TBC. The maximum selectivity to $4-\mathrm{TBC}$ in the presence of $2.5 \mathrm{wt} \%$ amount of the catalyst at $75{ }^{\circ} \mathrm{C}$ was $42 \mathrm{~mol} \%$ at the 4 -TBP conversion of $38 \mathrm{~mol} \%$.

In the presence of $10 \mathrm{wt} \%$ of the catalyst, the increase in temperature from 35 up to $75{ }^{\circ} \mathrm{C}$ led to the higher 4-TBP conversion from 25 to $54 \mathrm{~mol} \%$. The selectivity to 4 -TBC 
Table 2 Influence of the TSm-2 catalyst amount, temperature, and 4-TBP/ $\mathrm{H}_{2} \mathrm{O}_{2}$ molar ratio on the conversion of 4-TBP, $\mathrm{H}_{2} \mathrm{O}_{2}$, and the selectivity to $4-\mathrm{TBC}$

\begin{tabular}{|c|c|c|c|c|c|}
\hline Catalyst amount (wt\%) & $T\left({ }^{\circ} \mathrm{C}\right)$ & $4-\mathrm{TBP} / \mathrm{H}_{2} \mathrm{O}_{2}(\mathrm{~mol} / \mathrm{mol})$ & Conversion $\mathrm{H}_{2} \mathrm{O}_{2}(\%)$ & Conversion 4-TBP (mol\%) & $\begin{array}{l}\text { Selectivity 4-TBC } \\
(\text { mol wt } \%)\end{array}$ \\
\hline \multirow[t]{3}{*}{2.5} & 35 & $1 / 2$ & 23 & 11 & 35 \\
\hline & 50 & $1 / 2$ & 35 & 16 & 36 \\
\hline & 75 & $1 / 2$ & 76 & 38 & 42 \\
\hline \multirow[t]{5}{*}{10} & 35 & $1 / 2$ & 41 & 25 & 47 \\
\hline & 50 & $1 / 2$ & 79 & 38 & 52 \\
\hline & 75 & $1 / 1$ & 100 & 30 & 45 \\
\hline & & $1 / 2$ & 89 & 54 & 43 \\
\hline & & $1 / 4$ & 53 & 62 & 30 \\
\hline \multirow[t]{3}{*}{15} & 35 & $1 / 2$ & 58 & 32 & 48 \\
\hline & 50 & $1 / 2$ & 92 & 42 & 53 \\
\hline & 75 & $1 / 2$ & 100 & 38 & 40 \\
\hline
\end{tabular}

Reaction conditions: $\mathrm{c}^{0}(4-\mathrm{TBP})=0.12 \mathrm{~mol} / \mathrm{l}, 5 \mathrm{ml} \mathrm{CH} \mathrm{CH}_{3} \mathrm{CN}, 60 \mathrm{~min}$

Table 3 Stability test of TSm-2 catalyst

\begin{tabular}{llll}
\hline $\begin{array}{l}\text { Catalytic } \\
\text { cycle }\end{array}$ & $\begin{array}{l}\text { Conversion } \\
\mathrm{H}_{2} \mathrm{O}_{2}(\%)\end{array}$ & $\begin{array}{l}\text { Conversion } \\
(\mathrm{mol} \%)\end{array}$ & $\begin{array}{l}\text { Selectivity } \\
(\mathrm{mol} \%)\end{array}$ \\
\hline 1 & 89 & 54 & 43 \\
2 & 86 & 53 & 43 \\
3 & 86 & 53 & 44 \\
4 & 84 & 54 & 44 \\
5 & 85 & 53 & 43 \\
\hline
\end{tabular}

Reaction conditions: $10 \mathrm{wt} \%$ of $\mathrm{TSm}-2, c^{0}(4-\mathrm{TBP})=0.12 \mathrm{~mol} / \mathrm{l}$, $4-\mathrm{TBP} / \mathrm{H}_{2} \mathrm{O}_{2}=1 / 2(\mathrm{~mol} / \mathrm{mol}), 5 \mathrm{ml} \mathrm{CH}{ }_{3} \mathrm{CN}, 75^{\circ} \mathrm{C}, 60 \mathrm{~min}$

values was higher at the same 4-TBP conversion value, namely, the maximum the selectivity to 4 -TBC was $52 \mathrm{~mol} \%$ at the 4 -TBP conversion of $38 \mathrm{~mol} \%$ at $50{ }^{\circ} \mathrm{C}$.

An increase in the catalyst content from 10 up to $15 \mathrm{wt} \%$ at 35 and $50{ }^{\circ} \mathrm{C}$ allowed to maintain rather high 4-TBC formation selectivity values as well as the higher selectivity to 4-TBC.

An increase in the oxidizing agent quantity (the higher 4-TBP/ $\mathrm{H}_{2} \mathrm{O}_{2}$ molar ratio from $1 / 1$ to $1 / 4$ ) results in the slightly higher 4 -TBP conversion from 30 to $62 \mathrm{~mol} \%$; however, the selectivity to 4-TBC markedly decreases from 45 to $30 \mathrm{~mol} \%$.

It should be noted that no changes in 4-TBP conversion and the selectivity to 4-TBC were observed during the five catalytic cycles (Table 3), indicating that the catalyst was stable under reaction conditions. Moreover, no further 4-TBP conversion was exhibited in filtrate after removal of the catalyst. Thus, it was proved that the 4-TBP oxidation with $\mathrm{H}_{2} \mathrm{O}_{2}$ is a true heterogeneous process, during which no titanium leaching from the silicate matrix occurs [19].

The dependence of 4-TBP, 4-TBC, and tars content on reaction time was displayed in Fig. 8. The tars content

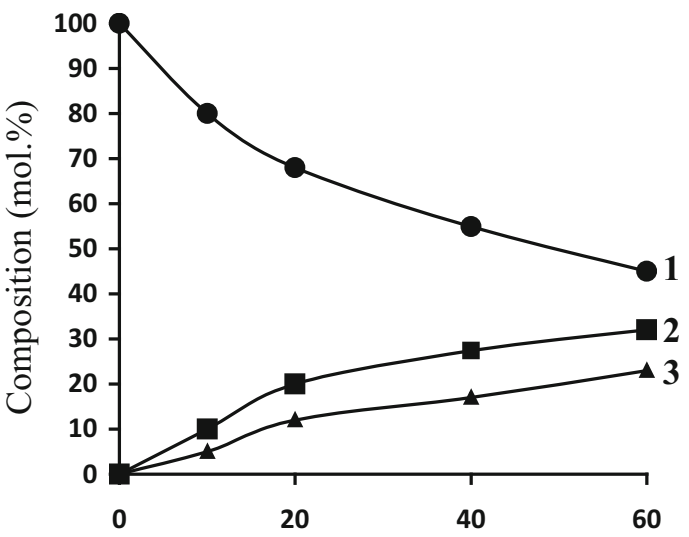

Fig. 8 Influence of the reaction time on the 4-TBP (1), 4-TBC (2), and tars (3) content (reaction conditions: $10 \mathrm{wt} \%$ of the TSm-2, $c^{0}(4-$ $\mathrm{TBP})=0.12 \mathrm{~mol} / \mathrm{l}, 4-\mathrm{TBP} / \mathrm{H}_{2} \mathrm{O}_{2}=1 / 2(\mathrm{~mol} / \mathrm{mol}), 5 \mathrm{ml}$ solvent, $\left.75^{\circ} \mathrm{C}, 60 \mathrm{~min}\right)$

changing indicated that the oxidative condensation products were formed at the initial time. It should be noted that 4-TBC also converted to oxidative condensation products with up to $80 \%$ conversion under the reaction conditions (10 wt $\%$ of TSm-2, $75{ }^{\circ} \mathrm{C}, 4-\mathrm{TBC} / \mathrm{H}_{2} \mathrm{O}_{2}=1 / 2,60 \mathrm{~min}$ ).

The following reaction scheme was proposed on the basis of these data (Fig. 9).

\section{Conclusion}

The influence of chemical and phase composition of the titanium-containing porous materials on their catalytic activity in the 4-tert-butylphenol oxidation with hydrogen peroxide in acetonitrile-aqueous solutions was investigated. 


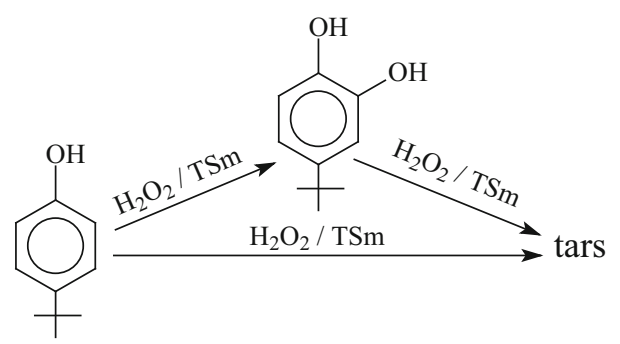

Fig. 9 Scheme of the 4-TBP oxidative transformations in the $\mathrm{H}_{2} \mathrm{O}_{2}$ acetonitrile-aqueous solutions over titanosilicate catalyst

The TS-1 microporous crystalline titanosilicate exhibited low activity in the 4-tert-butylphenol transformation in acetonitrile-aqueous $\mathrm{H}_{2} \mathrm{O}_{2}$ solutions due to the steric restrictions on the diffusion of the substrate molecules into the channels of the catalyst.

Mesoporous amorphous titanosilicates with the Ti content within the range of 1.0-3.7 wt\% showed good activity in the 4-tert-butylphenol conversion and the selectivity to 4-tertbutylcatechol. The maximum $53 \mathrm{~mol} \%$ selectivity to 4-tertbutylcatechol (4-tert-butylphenol conversion-42 mol\%) was reached at the temperature of $50{ }^{\circ} \mathrm{C}$ for 60 min reaction time in the presence of $15 \mathrm{wt} \%$ of the mesoporous titanosilicate containing $1.9 \mathrm{wt} \%$ of Ti.

Open Access This article is distributed under the terms of the Creative Commons Attribution 4.0 International License (http:// creativecommons.org/licenses/by/4.0/), which permits unrestricted use, distribution, and reproduction in any medium, provided you give appropriate credit to the original author(s) and the source, provide a link to the Creative Commons license, and indicate if changes were made.

\section{References}

1. Gogotov AF, Amosov VV, Tayursky VA, Ivanova AV, Voitik VS, Stankevich VK (2002) Scale tests of 4-tert-butylpyrocatechol as a polymer formation restraining agent in pyrocondensates. Prod Appl Elastomers 1:3-9

2. Gogotov AF, Amosov VV, Ivanova AV, Baranov OI, Puchenin EV, Vavilov AV, Stankevich BK (2004) Full-scale tests of tertbutylpyrocatechol as a restraining agent for producing EP-300 and "pyrotol" at the angarsk polymer plant. Oil Process Pet Chem 3:31-33

3. Ponomarenko VI, Tolstikov GA, Chausov SA, Irkhin BL, Levandovsky BT (1978) USSR Patent 592812

4. Xamis J, Nasek J (1964) Pyrocatechol alkylation. Chem Prumyst $14: 245-250$

5. Clerici MG, Kholdeeva OA (2013) Liquid phase oxidation via heterogeneous catalysis: organic synthesis and industrial applications. Wiley, New Jersey

6. Taramasso M., Perego G., Notari B. (1983) U.S. Patent 4410501

7. Wu P, Kubota Y, Yokoi T (2014) A career in catalysis: Takashi tatsumi. ACS Catal 4:23-30

8. Agliullin MR, Danilova IG, Faizullin AV, Amarantov SV, Bubennov SV, Prosochkina TR, Grigoreva NG, Paukshtis EA, Kutepov BI (2016) Sol-gel synthesis of mesoporous aluminosilicates with a narrow pore size distribution and catalytic activity thereof in the oligomerization of dec-1-ene. Microporous Mesoporous Mater 230:118-127

9. Veklov VA, Kutepov BI, Talipova RR, Grigorieva NG, Dzhemilev UM, Drozdov VA (2009) RU Patent 2422361

10. Karnaukhov AP (1999) Adsorption. Texture dispersed and porous materials. Nauka, Novosibirsk

11. Burkett SL, Davis ME (1995) Mechanisms of structure direction in the synthesis of pure-silica zeolites. 1. Synthesis of TPA/SiZSM-5. Chem Mater 7(5):920-928

12. Brinker CJ, Scherer GW (1990) Sol-gel science: the physics and chemistry of sol-gel processing. Academic Press, London

13. Corma A (1997) From microporous to mesoporous molecular sieve materials and their use in catalysis. Chem Rev 97:2373-2420

14. Ratnasamy P, Srinivas D, Knozinger H (2004) Active sites and reactive intermediates in titanium silicate molecular sieves. Adv Catal 48:1-169

15. Yoon CW, Hirsekorn KF, Neidig ML, Yang X, Tilley TD (2011) Mechanism of the decomposition of aqueous hydrogen peroxide over heterogeneous Ti-SBA-15 and TS-1 selective oxidation catalysts: insights from spectroscopic and density functional theory studies. ACS Catal 1:1665-1678

16. Kholdeeva OA, Zalomaeva OV (2016) Recent advances in transition-metal-catalyzed selective oxidation of substituted phenols and methoxyarenes with environmentally benign oxidants. Coord Chem Rev 306:302-330

17. Reddy JS, Sivasanker S, Ratnasamy P (1992) Hydroxylation of phenol over TS-2, a titanium silicate molecular sieve. J Mol Catal 71:373-381

18. Raihardt K (1991) Solvents and media effects in organic chemistry. Mir, Moscow

19. Sheldon RA (1997) Redox molecular sieves as heterogeneous catalysts for liquid phase oxidations. Stud Surf Sci Catal 110:151-175 